\title{
A SUPERAÇÃO DO MÉTODO TECNICISTA VISANDO A APROXIMAÇÃO DO ENSINO DO DIREITO COM A REALIDADE SOCIAL
}

\author{
Maria Vital da Rocha \\ Universidade Federal do Ceará (UFC) e Centro \\ Universitário 7 de Setembro (UNI7), Ceará. \\ mavitalrocha@gmail.com
}

Ana Luiza Barroso Caracas de Castro

Universidade Federal do Ceará (UFC), Ceará. analuizabccastro@gmail.com

\begin{abstract}
RESUMO: A ciência do Direito pode ser considerada, primordialmente, uma ciência social, porque visa estudar as necessidades advindas das interações entre os grupos que compõem a sociedade, buscando tutelar juridicamente essas relações por meio da concretização das normas jurídicas que, nada mais são, do que mandamentos institucionais advindos do poder estatal como uma medida de organização social. Entretanto, o positivismo vastamente enraizado em nossa cultura jurídica acaba por supervalorizar os textos legais que compõem o ordenamento jurídico pátrio, adotando-os como fonte primordial do Direito e, consequentemente, ignorando as diversas fontes que constituem o viés multifacetário do ensino jurídico. Desta feita, o presente trabalho possui o objetivo específico de abordar os problemas envolvendo o ensino jurídico, criticando o método tecnicista inerente à formação legalista do bacharel em Direito. Para elaboração deste trabalho, será realizada vasta pesquisa bibliográfica por meio de diversos periódicos em revistas, doutrinas, trabalhos científicos, dentre outros mais, com a citação de obras nacionais e estrangeiras, baseando-se, prioritariamente, nos ensinamos preconizados por Eugen Ehrlich, percussor dos estudos relacionados à Sociologia Jurídica. Conclui-se, a partir desta pesquisa, que o processo cognitivo da ciência do Direito e a transmissão de suas teorias por meio do ensino jurídico, devem ser aperfeiçoados com o uso de novas metodologias que invistam no diálogo entre os alunos e na consideração de outras fontes, com a sua devida interligação à outras ciências sociais, prioritariamente, a Sociologia Jurídica.
\end{abstract}

PALAVRAS-CHAVE: Ensino jurídico. Sociologia. Positivismo. Método Tecnicista. Processo cognitivo. Dialética.

\section{Overcoming the technician method aiming at approaching the teaching of law with social reality}

\begin{abstract}
The science of law can be considered, primarily, a social science, because it aims to study the needs arising from the interactions between the groups that make up society, seeking to legally protect these relationships through the realization of legal norms that are nothing more than institutional commandments arising from state power as a measure of social organization. However, positivism widely rooted in our legal culture ends up overvaluing the legal texts that make up the national legal system, adopting them as the primary source of law and, consequently, ignoring the various sources that constitute the multifaceted bias of legal education. This time, the present work has the specific objective of addressing the problems involving legal education, criticizing the technicist method inherent in the legal formation. For the elaboration of this work, a vast bibliographic research will be carried out by means of several journals in magazines, doctrines, scientific works, among others, with the citation of national and foreign works, based, as
\end{abstract}


a priority, on the teachings recommended by Eugen Ehrlich, percussor of studies related to Legal Sociology. It is concluded, from this research, that the cognitive process of the science of Law and the transmission of its theories through legal education, must be improved with the use of new methodologies that invest in the dialogue between the students and in the consideration of others sources, with its due interconnection to other social sciences, primarily, the Legal Sociology.

KEYWORDS: Legal education. Sociology. Positivism. Technicist Method. Cognitive process. Dialectics.

\section{INTRODUÇÃO}

A ciência do Direito pode ser considerada, primordialmente, uma ciência social, porque visa estudar as necessidades advindas das interações entre os grupos que compõem a sociedade, buscando tutelar juridicamente essas relações por meio da concretização das normas jurídicas, sistematizadas em princípios e regras que, nada mais são, do que mandamentos institucionais advindos do poder estatal como uma medida de organização social.

Acontece que, o pensamento positivista vastamente enraizado na cultura jurídica acaba por supervalorizar os textos legais que compõem o ordenamento jurídico pátrio, adotando-os como fonte primordial do Direito e, consequentemente, ignorando as diversas fontes que fundamentam o estudo jurídico, com respaldo nos fatos sociais que dão base para a evolução do conhecimento científico nessa área.

A visão positivista enseja a aplicação da metodologia tecnicista para o estudo do Direito, baseando-se no formalismo exacerbado e na análise das normas para a compreensão das teorias jurídicas, ignorando outras áreas das ciências sociais, como a Sociologia Jurídica, por considerar que a ciência jurídica deve ser apreendida de maneira apartada.

Diante disso, o objetivo específico do presente trabalho é pesquisar e, com isso, procurar soluções para os problemas que envolvem o ensino jurídico. A sistemática de ensino que envolve o direito tem o seu desenvolvimento prejudicado por uma metodologia acrítica e tecnicista, preocupada com a supervalorização do formalismo ligado ao positivismo jurídico, desprezando a importância do diálogo e do confrontamento de teorias na educação dos bacharéis em Direito.

Para elaboração deste trabalho, será realizada vasta pesquisa bibliográfica por meio de diversos periódicos em revistas, doutrinas, trabalhos científicos, dentre outros mais, com a citação de obras nacionais e estrangeiras. Este artigo se baseará, especialmente, nos ensinamentos preconizados por Eugen Ehrlich e suas teorizações acerca da Sociologia Jurídica, buscando alcançar o objetivo geral de demonstrar que o problema do ensino jurídico é a sua não adequação com a realidade social vigente, o que enseja o distanciamento dos juristas com as preocupações de caráter social, impossibilitando os instrumentos do Direito de atingir as suas finalidades humanísticas.

Adentrando à discussão sobre a temática a ser abordada, o primeiro tópico tem a finalidade de realizar uma análise sobre como o Direito é uma ciência que reflete a realidade social vigente e, por isso, o ensino jurídico deve, necessariamente, combater a visão positivista que defende a predominância do formalismo. O segundo tópico visa criticar o método tecnicista, amplamente aplicado no ensino superior de formação jurídica. Já o terceiro tópico, busca realizar um estudo epistemológico de como deve proceder a aquisição do conhecimento científico do 
Direito, propondo novas formas para a didática do ensino jurídico, devendo se basear na Sociologia, junto com as demais disciplinas humanistas, com a finalidade de superar uma formação sem percepção crítica e transformadora dos profissionais do Direito.

\section{O DIREITO É UM REFLEXO DA REALIDADE SOCIAL VIGENTE?}

O Direito nasce da interação entre os grupos sociais que compõem uma comunidade, nada mais é do que um reflexo das necessidades sociais momentâneas e a busca por respostas para os conflitos que emergem dessas interações, visando criar medidas de pacificação social. Euger Ehrlich (1986), o grande precursor da Sociologia Jurídica entende que o que nasce da normatização estatal é apenas uma pequena parcela do Direito, que nada mais é do que o reflexo da realidade social vigente e suas exigências e da aplicação prática da tutela jurisdicional aplicada por seus operadores.

O autor (EHRLICH, 1986) afirma que o desenvolvimento do Direito se dá a partir do surgimento e da transformação das instituições sociais, tendo estas como ponto de partida para a sua estruturação. Defende que a intervenção direta do poder de polícia ou as decisões judiciais emanadas por órgãos públicos competentes também conseguem influenciar no desenvolvimento do Direito, contudo, é impossível ignorar que a cada momento, nas sociedades modernas, são criadas instituições novas ou as já existentes investem em transformações para evoluir, independentemente das determinações advindas da legislação estatal; que, como medida de eficácia da tutela jurisdicional, deve buscar se adaptar à realidade que se apresenta, defendendo que "o Direito muda, porque mudam as pessoas e as coisas" (EHRLICH, 1986, p. 300). Complementa com uma crítica pertinente, em que o Direito positivado não acompanha a evolução social, que se dá de maneira cíclica e constante, apresentando novas necessidades e transformando os próprios costumes. Sendo assim, o âmbito jurídico acaba por se distanciar da realidade social, sob um viés conservador e atrasado.

Podemos dizer, a partir disso, que o Direito é a concretização de situações postas pela realidade social. Logo, mesmo sendo positivado por meio de normas, o âmbito jurídico acompanha o processo de construção e transformação social, nos seus aspectos políticos, econômicos, culturais e, principalmente, históricos. A realidade social é composta por particularidades, correspondendo assim, a instituições jurídicas específicas, "sobre as quais recaem os condicionantes sócio-culturais reforçados pelos costumes, pela moral e pelos valores sociais" (NOVAES, 2011, p. 05).

Sendo assim, o Direito não pode ser analisado sobre o viés concreto e enraizado do positivismo, mas sim, merece ser estudado com base em diversos fatores, que podem ser considerados como normatividades distintas, para além das normas concretas, que influenciam as relações sociais e, consequentemente, o comportamento jurídico e a adequação do Direito.

Os ensinamentos iniciados por Euger Ehrlich e perseguidos por tantos outros sociólogos e filósofos, vão de encontro com a teoria pura do Direito, inaugurada por Hans Kelsen (2015), em que a ciência jurídica deveria ser estudada e aplicada de maneira completamente apartada das outras ciências, inclusive as ciências sociais. Para ele, a pureza da ciência jurídica deve prevalecer como medida de obtenção de uma maior segurança jurídica, de que o Estado ficaria limitado aos mandamentos legais devidamente positivados, em que os operadores do direito estariam submetidos às regras estipuladas e os juízes funcionariam meramente como "bocas da lei", julgando estritamente de acordo com o ordenamento jurídico, podendo apenas decidir, de maneira mais discricionária, em caso de possíveis lacunas que venham a aparecer. Ao distinguir norma jurídica e proposição jurídica, afirma Hans Kelsen (2015, p. 80-81): 


\begin{abstract}
Na medida em que a ciência jurídica apenas apreende a conduta humana enquanto esta constitui conteúdo de normas jurídicas, isto é, enquanto é determinada por normas jurídicas, representa uma interpretação normativa destes fatos de conduta. Descreve as normas jurídicas produzidas através de atos de conduta humana e que hãode ser aplicadas e observadas também por atos de conduta e, consequentemente, descreve as relações constituídas, através dessas normas jurídicas, entre os fatos por elas determinados. As proposições ou enunciados nos quais a ciência jurídica descreve estas relações devem, como proposições jurídicas, ser distinguidas das normas jurídicas que são produzidas pelos órgãos jurídicas a fim de por eles serem aplicadas e serem observadas pelos destinatários do Direito. Proposições jurídicas são juízos hipotéticos que enunciam ou traduzem que, de conformidade com o sentido de uma ordem jurídica - nacional ou internacional - dada ao conhecimento jurídico, sob certas condições ou pressupostos fixados por esse ordenamento, devem intervir certas consequências pelo mesmo ordenamento determinadas.
\end{abstract}

De acordo com a teoria pura criada por Hans Kelsen (2015), há uma complexa preponderância da norma jurídica na aplicação da tutela jurisdicional, pois a norma deveria funcionar como uma moldura que, por meio da valoração jurídica, se adequaria aos fatos. Sendo assim, criticando a teoria kelseniana, percebe-se que por intermédio de seu próprio conceito, que sempre haveria a necessidade da valoração da realidade social apresentada por meio dos fatos, a partir da cognição firmada pelos operadores do Direito diante da demanda apresentada, para que se adequasse a norma devidamente. Em caso de lacuna, isso ficaria ainda mais evidente, visto que seria permitido ao julgador certo grau de discricionariedade. Portanto, mesmo que sua teoria proponha a "pureza" da ciência jurídica, não seria possível ignorar que a realidade fática advinda dos diversos âmbitos que abrangem a realidade social.

O formalismo aplicado de maneira exagerada acaba por dificultar a adequação do Direito com as relações sociais existentes, mediante uma visão estritamente positivista, Agostinho Marques Neto (2004) apresenta uma crítica pertinente sobre a aplicação do positivismo no processo de aquisição do conhecimento científico, afirmando que o "mito positivista" constantemente é utilizado nos Estados Modernos como uma forma de controle que favorece as classes dominantes em face das classes dominadas, tentando camuflar esse sistema de favorecimento desleal através do "manto ideológico" de segurança jurídica que é utilizado como instrumento de justificação para o pensamento positivista. O autor explica (MARQUES NETO, 2004, p. 47-48):

As ciências e suas aplicações práticas são apresentadas à população como se constituíssem novas religiões, como se suas verdades fossem não só inabaláveis como necessárias, tudo isso em nome de abstrações como o progresso, o desenvolvimento, o bem-comum. Tais abstrações visam a ocultar sutilmente o fato de que são as classes dominantes as grandes beneficiárias do desenvolvimento científico e tecnológico, sobrando geralmente para as classes dominadas o ônus de suportar as consequências desse desenvolvimento (poluição, inflação, escassez, etc.), sem dele tirarem praticamente qualquer proveito. Não é sem propósito que as atividades de pesquisa estão cada vez mais centralizadas em órgãos burocráticos do Estado - velho aliado das classes dominantes em qualquer sociedade de classes -, controladas por tecnocratas nem sempre possuidores de formação científica adequada, mas que estabelecem prioridades, financiam determinadas pesquisas e desestimulam outras, muitas vezes com o propósito evidente de não permitir que se ponha em xeque o sistema de poder estabelecido.

Sendo assim, o Direito não pode ser considerado como uma ordem normativa uniforme e singular, mas sim como uma ordem plural, pois é composto por diversos grupos com identidades e interesses distintos, e, por isso, deve buscar atender as demandas advindas desses diferentes contextos sociais que se apresentam, como medida de garantia do próprio Estado Democrático de Direito vigente no Brasil.

Manuel Rodriguez Lapuente (1996) critica a situação complicada em que se encontra a democracia moderna, pois a sociedade desse tipo de regime se organiza através da sua divisão 
em grupos de interesses específicos dentro da realidade Estatal, em seus diferentes âmbitos. Esses grupos formam uma complexa estrutura de classes sociais, profissionais, econômicas, políticas, religiosas, culturais, dentre outras mais. Como também, salienta que os meios de comunicação exercem um papel fundamental na interação entre esses grupos, podendo aproximá-los, ou tornar ainda mais acalorada e conflituosa a relação entre eles.

Boaventura de Sousa Santos (2009), ao abordar a sua experiência de três meses em uma comunidade carente na cidade do Rio de Janeiro/RJ, a qual denominou de Pasárgada, demonstrando a multinormatividade existente nessa comunidade e, a partir disso, os mecanismos adotados dentro do convívio social que superavam a ordem jurídica estatal, criando regras sociais de solução de conflito e de gestão dos serviços naquela comunidade que, sem dúvidas, complementam e, muitas vezes, sobrepõem o Direito posto, merecendo a tutela jurídica, mesmo sem a sua positivação na lei advinda do Estado.

O autor estuda a criação de normas internas dentro das comunidades carentes, explicando que essa normatividade surge para superar as demandas que a legislação estatal não consegue alcançar, buscando organizar o convívio dentro desses grupos sociais, com a finalidade de solucionar os conflitos que possam vir a existir. Essas ordens locais permitem o estabelecimento de institutos internos para a mediação de conflitos, que se justificam pela falta de prestação jurisdicional por parte do Estado na comunidade estudada. Portanto, como a lei estatal não alcança aqueles grupos sociais, por mero descaso do próprio poder público, torna-se necessária a regulação interna por parte das pessoas que habitam aquela localidade e sofrem com essa exclusão.

Boaventura de Sousa Santos (2009) traz uma visão de ordem das classes dominantes e da ordem das classes oprimidas, afirmando que tanto os procedimentos uniformes, como os padrões normativos, devem ser considerados como assuntos judiciais dentro de um grupo de uma determinada comunidade: "La justiciabilidad significa que los patrones normativos a los que me referiré son aplicados por um tercero imparcial, utilizando un concepto de amplia difusión em los trabajos de antropologia del derecho, en un contexto de conflicto y de conformidade con ciertos procedimentos uniformes" (SANTOS, 2009, p. 133).

Uma observação feita por Boaventura de Sousa Santos (2009) e que ele menciona no decorrer de toda a sua obra, é que a sociedade é composta por diversos grupos sociais, que agregam distintos interesses e possuem características próprias, em que, comumente, se dividem em classes dominantes e classes dominadas, criando uma relação paradoxal de interligação e segregação.

Concordando com as conclusões alcançadas a partir do estudo de Boaventura, José Fábio Rodrigues Maciel (2018) e Daniele Comin Martins (2008) afirmam que o pluralismo jurídico existe e se coloca acima da diversidade entre os grupos, pois é uma forma eficaz de suprir as lacunas da legislação posta pelo Estado que deixa por tutelar diversos grupos menos favorecidos dentro da dinâmica econômica e social, bem como, tanto supre apenas as necessidades meramente formais, ligadas à letra da lei, quanto supre as necessidades práticas do descaso do poder público com essa população menos favorecida. Sendo assim, podemos considerar o pluralismo jurídico mais uma demonstração de que o comportamento humano, dentro da realidade social, cria e transforma a normatização existente em determinada localidade, conforme brilhantemente explicado por Eugen Ehrlich.

José Fábio Maciel (2018) evidencia que o pluralismo permite que os mais variados grupos de uma sociedade convivam em harmonia, com atenção as suas necessidades, o que acaba por dar eficácia e segurança ao regime democrático adotado, que possui como finalidade a possibilidade de convivência entre as diferentes classes sociais, com a consideração das diferentes con- 
cepções de vida de seus indivíduos. O autor explica que o que se busca é uma sociedade igualitária e não igual, fazendo referência à ideia de igualdade material ${ }^{1}$, por meio da consideração das diferenças entre as classes sociais, que só pode ser alcançada com a abrangência do viés social. Esse trato só pode ser modificado a partir da transmissão do conhecimento jurídico.

Diante disso, encontra-se a permanente crítica ao legalismo exacerbado, de vertente positivista, que emergiu principalmente após o positivismo, em que a ideia de um Direito Comum e plural já havia sido superada. A unicidade do Direito, em que apenas a legislação estatal deve vigorar dentro dos limites territoriais a que se destina, é uma ficção que prejudica diretamente a diversidade cultural. Eugen Ehrlich (1986) critica as fontes do Direito, pois, corretamente, entende que elas restringem a abrangência de alcance do Direito, resumindo sua esfera à duas fontes: a lei e o costume. Essa teoria de duas fontes remonta ao Direito Comum, abarcado pelo direito Civil (Direito Romano) e o Direito Canônico, que tinham como fontes principais os códigos e os costumes.

José Fábio Maciel (2018, paginação irregular) cita de maneira sucinta: “aceitar a existência de outros direitos que não o imposto pelo Estado representa não só opor-se a uma única matriz cultural, mas também respeitar e proteger o direito à diferença, essencial para o futuro humano". Mariane Morato Stival (2019) salienta essa ideia defendendo que o individualismo no trato da ciência do Direito faz com que esta área deixe de se preocupar com outras áreas que também fazem parte da tutela jurisdicional. Esse individualismo de interesses faz com que as pessoas que compõem uma sociedade se preocupem, prioritariamente, com uma supervalorização de seus espaços de interesse e um afastamento de espaço e pessoas social e economicamente distantes.

Daniele Comin Martins (2008) critica os modelos epistemológicos utilizados pelo Direito, pois não conseguem dar conta da realidade existente, envolvendo a pluralidade social que se apresenta na modernidade ocidental, convergindo com a ideia de Euger Ehrlich. As teorias pluralistas, em suas perspectivas antropológicas e transnacionais, conquistam espaços de defesa do direito à diversidade, tornando o regime de Estado mais ampliado. Uma democracia só consegue atender a sua finalidade de atender as necessidades de todos, se se valer em teorias pluralistas.

Antônio Carlos Wolkmer (2018, p. 30) conceitua o pluralismo jurídico como um novo fundamento para a cultura do Direito, designando essa expressão como "una multiplicidad de manifestaciones o prácticas normativas en un mismo espacio sociopolítico, acionadas por conflictos e consensos, pudiendo ser o no oficiales y teniendo su razón de ser em las necessidades existenciales, materiales y culturales". A partir disso, preleciona que o pluralismo jurídico emancipador surge como uma possibilidade de preencher as lacunas epistemológicas deixadas pela vertente da unicidade jurídica de um direito positivado puro.

Nesse sentido, Mario Silvio Gerlero (2006, p. 339) expressa: "no basta el conocimiento de las leyes e el saber doctrinario sino ese conocimiento tiene que complementarse com otras áreas, entre ellas, no cabe dudas que se destaca la administración, la sociologia y la psicología”, destacando a necessidade dos operadores do direito, podendo considerar também aqueles que estão em fase de formação técnica para exercer alguma função jurídica, de sair dos limites formais de estudo da ciência jurídica, criando uma maior interação com outras áreas, considerando que, prioritariamente, o Direito é uma ciência social.

1 Igualdade material é a espécie de igualdade que visa tratar de maneira desigual aqueles que são diferentes, buscando reduzir as suas desigualdades. Essa ideia é a mais defendida, visto que os grupos sociais são extremamente desiguais entre si, conforme se explica no decorrer dessa obra, então, merecem ser tratados de maneira desigual, para que se efetive uma paridade de oportunidades e de participação entre eles. 
A partir disso, ressalta-se que, os instrumentadores do Direito, ao se valerem dos elementos inerentes à cognição humana para aplicar uma hermenêutica jurídica condizente com os mandamentos legais positivados, acabam por ignorar os costumes e as necessidades apresentadas pelos indivíduos que compõem a sociedade, o que pode vir a ocasionar uma grave instabilidade e insegurança dentro do Poder Judiciário, pois este, nesse ínterim, se distancia da sua finalidade de alcançar a harmonia entre os grupos sociais.

Portanto, as ferramentas para aprimorar o ensino jurídico devem ultrapassar as barreiras formais criadas por uma visão extremamente positivista do ordenamento jurídico, visando a formação de profissionais que atuem buscando a pacificação dos conflitos que venham a emergir das interações entre os grupos sociais.

\section{O MÉTODO TECNICISTA COMO UMA BARREIRA AO ENSINO JURÍ- DICO}

O tecnicismo consiste no estudo jurídico intermediado por um método onde o formalismo e o positivismo jurídico ganham destaque, partindo da ideia que a ciência do Direito é independente e, por isso, seus profissionais devem se ater aos textos expressos pelo ordenamento, sem adentrar na devida necessidade de debates críticos em relação aos seus conteúdos materiais.

Antes de iniciar a discussão sobre as críticas quanto ao método tecnicista, é importante ressaltar que o Direito é uma ciência social, logo, um método de aquisição do conhecimento baseado no engessamento das teorias utilizadas como paradigmas para a compreensão de seus preceitos, não condiz com a própria natureza dessa ciência.

Concordando com essa ideia, Hans Georg Gadamer (2005) propõe que a compreensão do Direito não pode ser conquistada a partir de uma métrica de transmissão de conhecimento, ao contrário, uma melhor compreensão dos preceitos jurídicos só poderia ser alcançada com o devido respeito ao processo cognitivo humano, por meio do uso da racionalidade e do constante embate racional entre as teorias, formando um "círculo hermenêutico" epistemológico. O autor preleciona que os intérpretes, ao aplicarem a hermenêutica jurídica, sofrerão a influência cognitiva de suas pré-compreensões, advindas de suas variadas origens históricas e de seus conhecimentos adquiridos pelo "senso comum". A partir disso, para a busca de um melhor domínio sobre os assuntos ligados ao ensino do Direito, os conhecimentos adquiridos devem se sujeitar à constantes reanálises, o que pode vir a ensejar a superação ou a manutenção das respostas hermenêuticas até então obtidas, afastando os preconceitos advindos de uma visão dogmática da ciência do Direito.

Roberto Lyra Filho (1982, p. 31) defende a dialética como a melhor medida para superar o formalismo exacerbado e, desse modo, a melhor maneira de aplicar a hermenêutica jurídica. Este autor critica uma interpretação que limite os fatos sociais "a esquemas prévios e mecânicos", pois essa metodologia seria simplória e não observaria os elementos históricos que envolvem determinada estrutura social, alcançando apenas uma "pseudociência". Em consonância, Rubens Limonji França (1988) salienta que a interpretação da ciência do Direito supera o positivismo legal, devendo, sempre, se adequar ao processo de transformação social, buscando tutelar as demandas que venham a emergir desse processo.

2 Johannes Hessen (2003) explica o "senso comum" como juízos cognitivos predeterminados, adquiridos por meio das interações sociais e históricas dos indivíduos, a partir de suas experiências cotidianas. 
Elizabete David Novaes (2005) traz uma importante crítica ao tecnicismo inerente à formação legalista do bacharel em Direito. Com razão, preleciona que o estudo jurídico deve se basear na Sociologia, junto com as demais disciplinas humanistas, com a finalidade de superar uma formação sem percepção crítica e transformadora por parte dos operadores da Lei, "decorrente de um positivismo normativista", conforme já fora explicado de maneira preliminar no tópico anterior.

A necessidade de uma formação transdisciplinar se dá porque o Direito é multifacetário, pluridimensional e complexo, direcionado a atender as necessidades humanas e regular as relações interpessoais, "como instrumento não somente de repressão, mas também (e principalmente) de mudança e transformação". Elizabete Novaes (2005, p. 02) complementa, ao explicar sobre a necessidade da adequação do ensino jurídico com um viés de debate sociológico:

\begin{abstract}
Podemos afirmar que a Sociologia, voltada para a compreensão do fenômeno jurídico, representa um importante passo para uma concepção dialética do Direito, compreendido, portanto, como processo - capaz não só de representar os interesses dominantes das estruturas sociais vigentes, mas, principalmente, caminhar para a ruptura dessas estruturas.
\end{abstract}

Como já fora introduzido no tópico anterior, o Direito não é, e não podemos considerar como se fosse, emanado pelo Estado, dando enseja à uma formação jurídica positivo-normativa. Nesse contexto, o pensamento positivista fortalece o método tecnicista, tanto na construção das doutrinas jurídicas, quanto na transmissão dos conhecimentos científicos nessa área, "impondo uma padronização da linguagem e da leitura dos códigos, justificando e reproduzindo a realidade social” (NOVAES, 2005, p. 02).

Logo, o Direito integra um universo social que transcende sua estrutura normativa, por isso, deve sempre superar suas próprias barreiras. Diante disso, a metodologia tecnicista não é a ideal, exatamente porque ignora a pluralidade das fontes que formam o Direito, antes mesmo que se efetive o sistema jurídico por meio da positivação das normas que compõem o ordenamento pátrio, impossibilitando a compreensão do viés histórico e cultural que delimitam diversas demandas de controle social. Sobre os problemas ligados à aplicação do tecnicismo, explica Ana Luiza Castro (2016, paginação irregular):

As normas do ordenamento jurídico devem ser submetidas a constantes análises, não
podendo simplesmente serem aceitas pelos operadores do Direito e pela população
que é regida por elas, ou seja, os sujeitos que vivenciam essas normas devem ser
vigilantes e reivindicar o máximo de liberdade possível em relação à aquisição de
conhecimento dentro dos meandros normativos, para que com isso, a hermenêutica
jurídica possa atender as prerrogativas dos fatores sociais que devem ser protegidos
pelo Direito.

Euger Ehrlich (1986) discorre que o jurista possui uma visão de mundo limitada pelas ideias de "direito" e "coerção jurídica", baseando-se simplesmente nas prescrições jurídicas, sendo incapaz de conceber a convivência humana sem a presença desses dois elementos. Preleciona: "Na sua maneira de pensar, ordem jurídica, tribunal, coerção jurídica formam uma unicidade e ele falará de direito e de condições jurídicas somente onde encontrar um tribunal e coerção jurídica ou, no mínimo, órgãos administrativos e coação administrativa" (EHRLICH, 1986, p. 69).

O estudo da ciência do Direito, seguindo a ideia de Miguel Reale (2002), e até mesmo anterior a ele, baseia-se na ideia de "fato", "valor" e "norma", contudo, o ensino jurídico supervaloriza a norma, deixando de investir em uma percepção empírica dos fenômenos jurídicos, que devem se adequar aos casos concretos. 
Esse método tecnicista, firmado apenas sob uma perspectiva metódica e positivista, acaba criando entraves para a formação de profissionais que coloquem em prática o pensamento crítico e racional, que é a principal ferramenta para o desenvolvimento de um bom cientista na área jurídica, porque a adoção de um comportamento dogmático, no trato das teorias do Direito, não permitem a evolução dessas ciências, já que ficam adstritos à um único pensamento, firmado por meio do estudo e da replicação dos textos expressos nas normas jurídicas.

O conhecimento dogmático baseia-se em verdades postas como absolutas ${ }^{3} \mathrm{e}$, por isso, difundem teorias sem respaldo científico, já que estas não foram submetidas a nenhum método de tentativa e erro $^{4}$, visto que foram simplesmente aceitas, sem que houvesse margem para, através de discussões devidamente aplicadas por meio da dialética, pudessem atestar a sua pertinência. O método tecnicista, ao replicar as teorias do Direito, sem abrir margem para contestações críticas, acaba explicando o desconhecido por meio de proposições dogmáticas que simplesmente serão aceitas pelos estudiosos em processo de formação, impedindo-os de ampliar seus conhecimentos por meio da investigação dessas proposições. "Desde el momento en que se aceptan las proposiciones dogmáticas como verdad absoluta, lo desconocido no está ya aterrando al hombre ni acosándolo, ni siquiera incitándolo a ampliar su horizonte conociendo más, sino que ha sido substituido por el dogma" (AFTALIÓN; VILANOVA; RAFFO, 2004, p. 34). Então, a atitude dogmática é prejudicial para o processo de aquisição do conhecimento jurídico.

Para além disso, percebe-se que o método tecnicista também não ensina os mecanismos eficientes para que os profissionais do Direito consigam superar as constantes lacunas que se manifestam a partir das transformações sociais, visto que, nos casos em que elas se apresentam, o hábito (conceito ligado ao costume) é o que determina as medidas e decisões que poderão ser tomadas, exigindo dos juristas uma boa proximidade com outras áreas das ciências sociais, usufruindo dos elementos comunicativos para a interação com as demandas da comunidade.

Emile Durkheim (2009), olhando esse aspecto multifacetário da formação do Direito e sua repercussão advinda dos sistemas sociais, fundamentou a "Sociologia do Direito" como o estudo do controle social que tem como essência a compreensão da realidade social como um todo. Ao abordar a relevância do viés sociológico para a compreensão das normas e do próprio estudo jurídico, Elizabete Novaes preleciona (2005, p. 03):

\begin{abstract}
Compreendendo que as leis são fenômenos sociais, historicamente construídos, é possível afirmarmos que há causas sociais para a existência de determinadas leis, bem como efeitos ou consequências sociais destas leis sobre a realidade social em que são forjadas. Em outras palavras, a sociologia investiga o impacto social das leis numa dada sociedade. Não se trata de observar ou julgar valorativamente as leis (o que é papel da filosofia do direito) e sim, investigar os valores sociais que nutrem a existência de determinadas leis, bem como sua eficácia social. Desse modo, apontamos para a importância da pesquisa científica de cunho sociológico, que seja voltada para o universo jurídico, envolvendo estudos de representações sociais, percepção de valores e expectativas sociais acerca do direito, da justiça, das leis e inovações jurídicas.
\end{abstract}

Desta feita, observa-se que a Sociologia consegue interligar o direito positivado e seu formalismo exacerbado com a realidade social, diminuindo o distanciamento entre essas questões, possibilitando que as normas jurídicas sejam aplicadas de maneira eficaz. Roberto Lyra

\footnotetext{
3 Verdades absolutas, neste caso, refere-se às ideias que são aceitas sem uma discussão prévia a respeito do assunto; que são aceitas sem que se possa abrir margem para maiores críticas e discussões, através da dialética, por exemplo.

4 Karl Popper (2004) explica que para que seja verificada a falibilidade de uma teoria, ou seja, para que se ateste se uma teoria é coerente com a realidade ou não, torna-se necessário que tal ideia seja submetida à diversas verificações, sendo constantemente falseada, para que assim, possa se atestar a sua pertinência ou comprovar a sua fragilidade.
} 
Filho (1982, p. 32-33) ressalta a importância de uma análise dialética entre a ciência do Direito e outras ciências: "A História registra o concreto-singular, a Sociologia o aborda na multiplicidade - generalizada em modelos, segundo os traços comuns"; bem como, "Aplicando-se ao Direito uma abordagem sociológica será então possível esquematizar os pontos de integração do fenômeno jurídico na vida social, bem como perceber a sua peculiaridade distintiva, a sua "essência" verdadeira". Sendo assim, os cursos de graduação na área jurídica não só devem trazer a Sociologia como uma disciplina obrigatória e incentivar trabalhos escritos abordando as temáticas relacionadas com essa ciência, como também, devem buscar interligar o estudo das mais variadas disciplinas que tratam sobre os direitos materiais e os seus pressupostos com a realidade social que se observa, para que assim, os profissionais do Direito possam atender melhor às necessidades que precisam de sua tutela. Por causa disso, o estudo do Direito não pode ser apartado do estudo da Sociologia, visto que a relação entre essas ciências conseguiria suprir as demandas sociais advindas da contraposição de interesses dos diversos grupos sociais específicos, por meio da consideração do caráter social e histórico do Direito, que compõem a sua essência.

O caráter social do direito deve ser o fundamento primordial para a formação dos profissionais dessa área, como garantia da igualdade e manutenção da justiça. É fundamental para a formação de um bom jurista que este tenha consciência do caráter flexível, dialético e adaptável a mobilidade social do Direito, superando não só o formalismo das leis, como uma concepção conformadora da prática jurídica que apenas visa repetir precedentes já firmados, que impedem a evolução da ciência jurídica e a refutação de suas próprias teorias. O Direito nasce do conflito entre os grupos sociais, e possui a responsabilidade de tutelar essas demandas superando as desigualdades existentes entre essas classes. Por isso, o processo deve ser visto como um meio de progresso histórico e transformação social.

Nessa perspectiva do Direito como um meio de libertação das classes sociais, por meio da tutela de suas necessidades, destaca-se que essa transformação só pode ser alcançada por meio da demonstração dos diversos pontos de vista das partes adversárias dentro do processo, com a valorização do contraditório e dos diversos instrumentos da dialética. Portanto, o ensino jurídico deve se basear não só no estudo dos mandamentos legais, que também são importantes, mas, predominantemente, no estudo da dialética, das questões históricas e da Sociologia, se preocupando com cada conflito social que veio a originar determinada demanda, para que assim, os profissionais da área adquiram tanto a capacidade técnica, como a capacidade crítica para oferecer saídas mais igualitárias e eficazes. O profissional do Direito possui um papel fundamental dentro das lutas democráticas sociais.

\section{A IMPLEMENTAÇÃO DE UMA NOVA METODOLOGIA DE ENSINO BASEADA NA DIALÉTICA}

Por todos os problemas descritos envolvendo a metodologia aplicada para o ensino do Direito, em que se afasta a adequação com a realidade social existente em nome da supervalorização das normas positivadas e do formalismo extremo e conservador, o que cria um entrave epistemológico para a evolução ciência do Direito, Enrique R. Aftalión, José Vilanova e Julio Raffo (2004) afirmam que a produção do conhecimento jurídico deve se dar a partir do momento que os pesquisadores exercem sua "capacidade crítica" na análise dos elementos da vida cotidiana. Os autores explicam que o conhecimento não é o conjunto de enunciados verdadeiros, mas sim, uma atitude; atitude esta que reconhece a não existência de verdades absolutas e, por isso, as teorias advindas dos textos normativos devem sempre ser refutadas. 
Para Gaston Bachelard (1996), o conhecimento deve ser visto como um fenômeno peculiar de consciência que se fundamenta na autorreflexão constante sobre experiências trazidas pela realidade prática ou teórica.

Michele Taruffo (2009) preleciona que para a compreensão das teorias jurídicas de maneira mais próxima da realidade, torna-se necessário o estudo dos fatos, a partir de uma análise das demandas sociais, para que assim, seja possível atingir a pacificação dos conflitos que se apresentam. O conhecimento científico não é uma cópia sofisticada dos fatos, mas sim, estruturas teóricas que agem e transformam os fatos. O conhecimento percebido através dos fatos cria presunções (RESCHER, 2006), que nada mais são do que a crença de veracidade sobre determinada teoria, que não deve ser adotada de modo petrificado, com a conformação do resultado obtido por meio desta teoria; ao contrário, a atitude do cientista do Direito deve buscar derrotar tais presunções, confrontando-as com novas teorias que venham a surgir por meio de novos fatos sociais.

O método científico a ser aplicado para superar o comportamento tecnicista por profissionais e estudiosos do Direito, seria o método de tentativa e erro baseado no constante falseamento das presunções já adotadas, ou seja, baseado na verificação constante a respeito da validade de determinada teoria. A teoria falibilista preconizada por Karl Popper (2004) determina que, para se alcançar um conhecimento verdadeiramente seguro e científico, as presunções adotadas como corretas devem sempre ser questionadas, ou seja, a atitude do pesquisador deve sempre buscar falsear, mediante refutações, as teorias que são aceitas como verdadeiras. Caso se comprove, por meio da tentativa de falsificação, que determinada ideia é válida, isso é positivo para o avanço científico, pois as teorias aceitas se tornam ainda mais fortes (ainda devendo se sujeitar a possíveis refutações, para não se adote uma atitude dogmática); entretanto, caso uma teoria venha a ser derrotada por outra, isso também é extremamente produtivo para a construção da ciência jurídica, já que uma ideia válida irá superar uma ideia que não merece mais ser aplicada.

O falibilismo deve ser aplicado às ciências sociais, inclusive ao ensino jurídico, que possui como finalidade atingir uma racionalidade emancipatória por meio de seus pesquisadores e profissionais, derrotando as teorias adotadas como verdadeiras, que muitas vezes advém do estudo dogmático do texto normativo, sob o viés positivista, buscando atender as demandas da comunidade a partir dos fatos demonstrados pela realidade social.

Mas como o método de falseamento das teorias jurídicas pode ser aplicado na prática? A resposta para esse questionamento seria a dialética que se consolida por intermédio dos instrumentos de comunicação e interação social. $\mathrm{O}$ ensino jurídico baseado nos aspectos fáticos da realidade social, abrangendo a área de estudo da Sociologia Jurídica, traria um viés humanizado para a ciência jurídica. E, para que a interação entre essas ciências sociais possa existir de maneira eficiente, é necessário o estímulo da dialética entre os pesquisadores e operadores do Direito, pois, apenas com o intermédio dos instrumentos de comunicação, os pontos de vistas e as teorias poderiam ser refutadas.

A partir do avanço nos estudos na área da Sociologia, Jurgen Habermas (2003) preleciona que o paradigma para a aquisição do conhecimento científico não deve ser a consciência, mas sim a comunicação, pois são as relações sociais que possibilitam o avanço das teorias científicas e essas relações se consubstanciam por meio da linguagem e de instrumentos de comunicação. Explica que as divergências culturais e o embate entre teorias só pode ser plenamente resolvido mediante os mecanismos linguísticos, que permitem, de maneira satisfatória, a compreensão dos indivíduos sobre determinada presunção considerada verdadeira, com o devido confronto de seus entendimentos. 
A instigação do pensamento racional e crítico por parte dos estudantes da área jurídica é essencial para a independência da consciência desses indivíduos e, consequentemente, de seus debates. Esses debates acarretariam no falseamento de diversas presunções adotadas a partir do estudo das normas jurídicas. Logo, o uso da dialética dentro dos ensinamentos em sala de aula, estimulando os alunos a travarem debates sobre os diferentes pontos de vista de um processo, por exemplo, ensejariam um aprimoramento das teorias científicas adotadas como certas na área do Direito.

Hugo de Brito Machado Segundo (2016, p. 64) preleciona que "quando se cogita de um estudo do Direito visto a partir de sistema de normas através das quais ele se expressa ou exprime, é preciso lembrar, de início, que as normas são realidades institucionais", exatamente porque são emanadas pelo poder estatal e, por isso, devem se sujeitar ao raciocínio falibilista, buscando a refutação ou reafirmação de seus preceitos materiais, com base nos fatos advindos da realidade social e dos valores adotados culturalmente pela comunidade.

O Direito é um reflexo das relações sociais e, por isso, não pode ser visto como algo concreto e determinado, exatamente porque a sociedade é composta por diversos espaços, sendo a sua formação influenciada por âmbitos distintos, tratados por Niklas Lhumann (1995) em sua Teoria dos Sistemas. Preconizando a teoria geral dos sistemas sociais, Niklas Luhmann (1995) afirma que a sociedade se apresenta como um sistema de ordem maior em relação aos outros, exatamente porque abrange todas as interações humanas, que dependem diretamente dos mecanismos de comunicação para alcançar sua capacidade própria.

Francisco Renato Collyer (2019) acredita que sistema social, dentre os outros sistemas autopoiéticos, é o que mais se interliga ao sistema jurídico. Considerando a Teoria dos Sistemas elaborada por Luhmann, o autor destaca a importância da comunicação como elemento fundamental para a vida em sociedade, característica importante tanto para a interação entre os indivíduos, quanto para a definição da cultura ali existente. Diante disso, torna-se evidente a importância desse elemento também para a transmissão do conhecimento jurídico, adequando o Direito às práticas culturais e exigências sociais, formando profissionais que consigam trabalhar criticamente em meio aos debates que lhe são apresentados, para que assim consiga valorar as normas jurídicas da maneira devida.

Partindo do pressuposto de que o ensino jurídico deve adotar os métodos dialéticos aplicados por outras ciências sociais, especialmente a Sociologia, incentivando o diálogo racional entre os profissionais em formação, adota-se a solução proposta por Eugen Ehrlich (1986) da importância da investigação de um "direito vivo", em que o estudo do Direito deve superar as prescrições jurídicas como objeto de pesquisa. Destaca a importância da investigação dos elementos culturais de determinada comunidade, bem como, suas necessidades apresentadas pelos grupos que compõem a sociedade. $\mathrm{O}$ autor critica o mecanismo adotado para a legislação dessas prescrições jurídicas (EHRLICH, 1986, p. 374):

\footnotetext{
As prescrições jurídicas nem pretendem oferecer um quadro completo das condições jurídicas. O jurista formula as prescrições jurídicas tendo em vista as necessidades práticas do momento; ele só se preocupa com o que lhe interessa por motivos práticos. Ele não perderá tempo em formular prescrições jurídicas referentes a objetos que estão fora de seu campo de interesses, possivelmente pelo simples fato de que não competem aos tribunais onde trabalha ou porque não interessam à sua clientela.
}

\footnotetext{
5 A expressão "direito vivo" aplicada por Eugen Ehrlich refere-se a ideia de que o Direito não deve se basear apenas nos mandamentos legais, se restringindo aos textos positivados, na realidade, o Direito deve utilizar como pressuposto a vida cotidiana das pessoas, se preocupando em tutelar as necessidades advindas das interações sociais.
} 
Sendo assim, a medida eficiente para superar as problemáticas advindas das normas jurídicas e de seu processo legislativo seria a dialética com temáticas pertinentes à outras áreas de conhecimento, principalmente a Sociologia Jurídica, com base nos fundamentos trazidos por Eugen Ehrlich, conseguindo interligar as ciências sociais para atingir a sua finalidade comum, que seria a tutela das questões humanas. Só assim, o viés egoístico e formal do método tecnicista, que pressupõe a valorização das prescrições legais acima das questões apresentadas pela realidade social, poderá ser superado.

\section{CONCluSÃo}

O método tecnicista consiste no estudo jurídico baseado, prioritariamente, no positivismo e no respeito à forma, ressaltando as normas como a fonte determinante do Direito, partindo da ideia que a ciência jurídica pode ser considerada "pura" e independente das outras ciências e, por isso, seus profissionais devem se ater aos textos expressos pelo ordenamento de maneira apartada das outras ciências sociais, sem adentrar na devida necessidade de debates críticos em relação aos seus conteúdos materiais.

Entretanto, essa metodologia acaba por formar profissionais despreocupados com a realidade social vigente, ignorando diversas fontes essenciais para a aquisição do conhecimento jurídico. Quando os profissionais passam a adotar os mandamentos legais como preceitos absolutos, as teorias do Direito passam a se basear em dogmas, o que distancia o âmbito jurídico de sua natureza científica. Desta feita, a percepção acerca dos fatos é necessária para a devida aplicação das normas legais, visto que, é a partir dessa compreensão que se criam presunções de como a tutela jurisdicional poderá alcançar a sua finalidade de pacificar os conflitos e atender as demandas sociais.

Diante disso, o ensino jurídico deve superar o método tecnicista, adotando novas engrenagens que permitam a formação crítica e racional dos profissionais do Direito. O novo método a ser implementado possui sua origem na teoria falibilista proposta por Karl Popper, que determina que o conhecimento científico deve se basear na constante refutação das teorias já firmadas, visando, por meio da superação ou reafirmação dessas teorias, a evolução científica.

Os embates entre as teorias deve se dar por meio da dialética, utilizando os instrumentos linguísticos de comunicação e interação social para que os juristas e estudantes do Direito possam debater as presunções criadas acerca do conhecimento jurídico, aprimorando assim, não só sua criticidade e consciência sobre os assuntos abordados, como também, as próprias teorias que se aplicam ao Direito e devem estar em constante transformação para se adequar as rápidas mudanças e necessidades sociais que se apresentam por meio da realidade fática.

Portanto, o processo cognitivo da ciência do Direito e a transmissão de suas teorias por meio do ensino jurídico, devem ser aperfeiçoados com o uso de uma nova metodologia que invista na interação entre os alunos e na consideração de fontes alternativas, respeitando o viés multifacetário que fundamenta o âmbito jurídico, com a sua devida interligação com outras ciências sociais, prioritariamente, a Sociologia Jurídica.

\section{REFERÊNCIAS}

AFTALIÓN, Enrique R.; VILANOVA, José; RAFFO, Julio. Introducción al derecho. Buenos Aires: Abeledo-Perrot, 2004. 
BACHELARD, Gaston. A formação do espírito científico: contribuição para uma psicanálise do conhecimento. Tradução Esteia dos Santos Abreu. Rio de Janeiro: Contraponto, 1996.

CASTRO, Ana Luiza Barroso Caracas de. O método tecnicista como um obstáculo à aplicabilidade da hermenêutica jurídica. XVI Encontro de Iniciação à docência. Universidade de Fortaleza, 2016.

COLLYER, Francisco Renato Silva. O espetáculo do telejornal e a (re)construção da opinião pública sob a perspectiva Luhmanniana. Disponível em: https://jus.com.br/artigos/66937/oespetaculo-do-telejornal-e-a-re-construcao-da-opiniao-publica-sob-a-perspectiva-luhmanniana/1. Publicado em jun. 2018. Acesso em 23 set. 2019.

CORREAS, Óscar. Crítica da ideologia jurídica: ensaio sócio-semiológico. Porto Alegre: Sérgio Antônio Fabris, 1995.

CRETELLA JR., José. Primeiras lições de direito. Rio de Janeiro: Forense, 2005.

DURKHEIM, Emile. Sociology and philosophy. London: Taylor \& Francis e-Library, 2009.

EHRLICH, Eugen. Fundamentos da sociologia do direito. Trad. De René Ernani Gertz. Brasília, Editora Universidade de Brasília, 1986, c1967.

GADAMER, Hans-Georg. Verdade e Método. Tradução de Flávio Paulo Meurer. 7. ed.. Petrópolis: Vozes, Bragança Paulista: Editora Universitária São Francisco, 2005.

GERLERO, Mario Silvio. Introducción a la Sociologia Jurídica: actores, sistemas y gestión judicial. Buenos Aires: David Grimberg, 2006.

HABERMAS, Jürgen. Truth and justification. Translated by Barbara Fultner. Massachusetts: MIT Press, 2003.

HESSEN, Johannes. Teoria do conhecimento. Trad. João Vergílio Gallerani Cuter. São Paulo: Martins Fontes, 2003.

KELSEN, Hans. Teoria pura do Direito. Trad. João Baptista Machado. São Paulo: Martins Fontes, 2015.

LAPUENTE, Manuel Rodriguez. Sociologia Del Derecho. México: Porrúa, 1996, pp. 107-133.

LIMONJI FRANÇA, Rubens. Hermenêutica Jurídica. 2. ed. rev. e ampl. - São Paulo: Saraiva, 1988.

LUHMANN, Niklas. Social Systems. California: Stanford University Press, 1995.

LYRA FILHO, Roberto. O que é Direito. 2. ed. São Paulo: Brasiliense, 1982b.

MACHADO SEGUNDO, Hugo de Brito. O direito e sua ciência: uma introdução à epistemologia jurídica. São Paulo: Malheiros, 2016.

MACIEL, José Fábio Rodrigues. Pluralismo e Unicidade na Busca de Segurança Jurídica, in Revista de Sociologia Jurídica, Número 6. Jan./Jun. 2018.

MARQUES NETO, Agostinho Ramalho. A ciência do direito: conceito, objeto, método. 2 ed. Rio de Janeiro: Renovar, 2004.

MARTINS, Daniele Comin. Pluralidade e Pluralismo: Breve incursão nas teorias pluralistas do Direito, in Revista de Sociologia Jurídica, Número 6. Jun./Jun. 2008. 
NOVAES, Elizabete David. Perspectiva Sociológica e Pluralismo Jurídico: a necessidade de superação do bacharelismo tecnicista na formação do profissional do direito. In Revista de Sociologia Jurídica, n. 1. jul./dez. 2005.

POPPER, Karl. A lógica das ciências sociais. Tradução de Estévão de Rezende Martins. 3.ed. Rio de Janeiro: Tempo Brasileiro, 2004.

REALE, Miguel. Lições preliminares de direito. 27 ed. São Paulo: Saraiva, 2002.

RESCHER, Nicholas. Presumption and the practices of tentative cognition. Cambridge: Cambridge University Press. 2006.

SANTOS, Boaventura de Sousa. Sociología jurídica crítica: para um nuevo sentido común en el derecho. Madrid/Bogotá: Trotta/ILSA, 2009.

STIVAL, Mariane Morato. Confiança e medo nas cidades globais: considerações acerca do pensamento de Zygmunt Bauman. Disponível em: https://jus.com.br/artigos/40918/confianca-emedo-nas-cidades-globais-consideracoes-acerca-do-pensamento-de-zygmunt-bauman. Acesso em: 8 out. 2019.

TARUFFO, Michele. La simplice verità. Il giudice e la costruzione dei fatti. Roma: Laterza, 2009.

WOLKMER, Antonio Carlos. Pluralismo jurídico: fundamentos de una nueva cultura del Derecho. $2^{\text {a }}$ ed. Madrid: Dykinson, S.L., 2018.

Recebido em: 12 fev. 2020.

Aceito em: 15 maio 2020. 